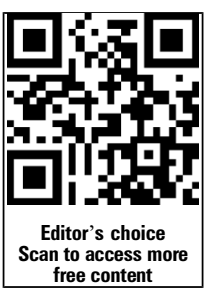

Scan to access mo free content

${ }^{1}$ Football Research Group, Linköping University, Linköping, Sweden ${ }^{2}$ Division of Community Medicine, Department of Medical and Health Sciences, Linköping University, Linköping, Sweden ${ }^{3}$ Department of Orthopaedics, Hässleholm-Kristianstad-Ystad Hospitals, Hässleholm, Sweden ${ }^{4}$ Division of Physiotherapy, Department of Medical and Health Sciences, Linköping University, Linköping, Sweden

\section{Correspondence to} Dr Markus Waldén, Division of Community Medicine, Department of Medical and Health Sciences, Linköping University, Linköping 581 83, Sweden; markus.walden@telia. com

Accepted 8 March 2016 Published Online First 31 March 2016

\section{Linked}

- http://dx.doi.org/10.1136/ bisports-2015-095359

- http://dx.doi.org/10.1136/ bjsports-2015-095501

\section{CrossMark}

\author{
To cite: Waldén $M$, \\ Hägglund $\mathrm{M}$, Magnusson $\mathrm{H}$, \\ et al. Br J Sports Med
} 2016:50:744-750.

\title{
ACL injuries in men's professional football: a 15-year prospective study on time trends and return-to-play rates reveals only $65 \%$ of players still play at the top level 3 years after $A C L$ rupture
}

\author{
Markus Waldén, ${ }^{1,2,3}$ Martin Hägglund, ${ }^{1,4}$ Henrik Magnusson, ${ }^{1,4}$ Jan Ekstrand ${ }^{1,2}$
}

\begin{abstract}
Background Studies investigating the development of $\mathrm{ACL}$ injuries over time in football are scarce and more data on what happens before and after return to play (RTP) are needed.
\end{abstract}

Aim To investigate (1) time trends in ACL injury rates, (2) complication rates before return to match play following $A C L$ reconstruction, and (3) the influence of $\mathrm{ACL}$ injury on the subsequent playing career in male professional football players.

Methods 78 clubs were followed between 2001 and 2015. Time trend in ACL injury rate was analysed using linear regression. $\mathrm{ACL}$-injured players were monitored until RTP and tracked for 3 years after RTP.

Results We recorded $157 \mathrm{ACL}$ injuries, 140 total and 17 partial ruptures, with a non-significant average annual increase in the $A C L$ injury rate by $6 \%\left(R^{2}=0.13\right.$, $b=0.059,95 \% \mathrm{Cl}-0.04$ to $0.15, p=0.20)$. The match $\mathrm{ACL}$ injury rate was 20 -fold higher than the training injury rate ( 0.340 vs 0.017 per $1000 \mathrm{~h}$ ). 138 players $(98.6 \%)$ with a total rupture underwent $A C L$ reconstruction; all 134 players with RTP data (4 players still under rehabilitation) were able to return to training, but 9 of them $(6.7 \%)$ suffered complications before their first match appearance ( 5 reruptures and 4 other knee surgeries). The median layoff after $A C L$ reconstruction was 6.6 months to training and 7.4 months to match play. We report 3-year follow-up data for 106 players in total; 91 players (85.8\%) were still playing football and 60 of 93 players (65\%) with $\mathrm{ACL}$ reconstruction for a total rupture played at the same level.

Conclusions The $A C L$ injury rate has not declined during the 2000s and the rerupture rate before return to match play was $4 \%$. The RTP rate within a year after $A C L$ reconstruction was very high, but only two-thirds competed at the highest level 3 years later.

\section{INTRODUCTION}

ACL rupture is a troublesome injury for a footballer and the long-term consequences such as early-onset osteoarthritis are well known. ${ }^{1}$ Interestingly, a recent study reported an increase in the number of annual ACL injuries recorded in Major League Soccer (MLS) from 1996 to 2012, ${ }^{2}$ although playing exposure was not taken into consideration. The rate of ligament injuries in general, including medial collateral ligament (MCL) injuries of the knee and ankle sprains, has declined substantially in European professional football during the past decade, ${ }^{3-5}$ but the development of ACL injury is not known.

There are several studies investigating return to play (RTP) after ACL injury or ACL reconstruction, ${ }^{2-9}$ including case reports of successful early returns after ACL reconstruction and non-surgical management. ${ }^{1011}$ Even if a majority of players can return to football after ACL injury/reconstruction, some sustain further knee problems and need further surgery. ${ }^{6}{ }^{12}$ From a medical perspective, a subsequent knee injury or the need for further knee surgery occurring in the final phase of the rehabilitation period or early after RTP could be regarded as a treatment failure. The extent of this problem is, however, essentially unclear from the current literature. In addition, although we have previously shown that the vast majority of ACL-reconstructed male professional players can return to the pitch within a year after surgery, ${ }^{8}$ the longer term participation rate is unknown.

We therefore conducted this study on men's professional football over 14 seasons with the goal of reporting (1) time trends in ACL injury rates, (2) complication rates before return to match play following ACL reconstruction, and (3) the influence of ACL injury on the subsequent playing career.

\section{MATERIALS AND METHODS}

This is a substudy of a long-term prospective cohort study evaluating men's professional football in Europe since 2001. ${ }^{13}$ A total of 78 clubs with 4443 individual players from the highest national leagues in 16 countries were followed over a varying number of seasons from January 2001 to May 2015 (365 club-seasons and 10157 playerseasons included for analysis). The general methodology for the injury surveillance has been reported in detail elsewhere. ${ }^{15}$

\section{Sample}

All players belonging to the first team squads each season were eligible for inclusion. ${ }^{16}$ Players who were transferred to other clubs or finished their contracts due to other reasons before the end of a season were included in the general injury and playing-exposure registration for as long as they played for the club.

\section{Definitions}

Injury was defined according to the time-loss concept. ${ }^{15}$ ACL injury was defined as a first-time or recurrent partial or total rupture of the ligament 
occurring either isolated or associated with other concomitant injuries to the knee joint. ${ }^{8}$ RTP was defined as the number of days from injury or reconstruction to full training with the team without restrictions (return to training) and to the first match appearance with the first team, reserve team, under-21 team or a national team (return to match play). Return to the same level of play was defined as return to the highest national league level, irrespective of country, and to lower level of play as all levels below the highest national league. The injury was classified as career ending if the player did not return to football at all.

\section{Data collection}

A member of the club medical or coaching staff registered individual playing-exposure in minutes during all club and national team training sessions and matches. Injury cards and attendance records were sent to the study group controller once a month. For each ACL injury reported, a standard ACL injury report form was emailed to the club medical staff requesting details on, for example, any previous ACL injury, MRI findings and surgical data.

All ACL-injured players were followed until RTP or the decision to end the playing career. RTP dates were taken automatically from the attendance record if the player was still in the study or via the medical staff if the club or the player was no longer in the study at the time of RTP. Players were followed closely to monitor any reruptures or surgeries of the ACL-injured knee during the rehabilitation period and after return to training in order to identify any possible reasons for prolonging the time to full RTP.

To evaluate the influence of the ACL injury on the short-term playing career, players' club track records were followed for 3 years after RTP even if they left the club or study during this period. The 3-year follow-up track records were identified through the clubs' official websites and, if further information was needed, via http://www.transfermarkt.co.uk. To be included in this 3-year analysis, a player had to return to football at the latest on 30 November 2012.

\section{Statistical analyses}

Data were analysed using SPSS (IBM SPSS Statistics for Windows, V.22.0, IBM Corp, Armonk, New York, USA). Injury rate was calculated as the number of injuries per $1000 \mathrm{~h}$ with corresponding 95\% CI. Injury rates were compared using a rate ratio (RR) with 95\% CI and significance tested with z-statistics. ${ }^{17}$ Time trend for ACL injury rate, expressed as the average annual percentage of change, was analysed using a linear regression model with log-transformed injury rates as the dependent variable. ${ }^{3}$ In addition, a 2-year moving average (MA) approach, by summarising two consecutive seasons, was also used as a sensitivity analysis to smooth out any large seasonal variations. $^{3}$

The RTP rate was calculated as the percentage of ACL-injured or ACL-reconstructed players who returned to football training and match play. ${ }^{8}$ The complication rate was calculated as the percentage of ACL-reconstructed players who suffered further knee injury or underwent further knee surgery during the rehabilitation period and after return to training. ACL-injured or ACL-reconstructed players were tracked for 3 years after RTP in order to calculate the percentage of players who were still competing at the highest national level. Layoff times were presented as median values with a corresponding IQR. For players with more than one ACL injury (graft rerupture or contralateral ligament rupture) recorded in the injury surveillance, only the first ACL injury was used in the 3-year follow-up. Average age was reported as the mean with corresponding SD and group differences tested with an unpaired Student's t test. All analyses were two sided and the significance level was set at $\mathrm{p}<0.05$.

\section{RESULTS}

A total of 157 ACL injuries in 149 players, including six reruptures and two contralateral ruptures, were recorded during the study period (2 026211 training hours and 361702 match hours) giving an overall ACL injury rate of 0.066 per $1000 \mathrm{~h}$ (table 1). The total rupture rate was significantly higher than the partial rupture rate $(0.059$ vs 0.007 per 1000 h; RR 8.2, 95\% CI 5.0 to $13.6, \mathrm{p}<0.001)$. The match ACL injury rate was 20 times higher than the training injury rate $(0.340$ vs 0.017 per $1000 \mathrm{~h}$; RR 20.4, 95\% CI 13.9 to $29.6, \mathrm{p}<0.001)$. Mean (SD) age for the 140 players with total rupture was 24.7 (4.5) years, and for the 17 players with partial rupture it was 26.6 (4.5) years.

\section{Time-trend analyses}

The number of ACL injuries recorded per season varied between 1 and 19 for match injuries and between 0 and 7 for training injuries. The trend in the linear regression model indicated an average annual increase of $6.0 \%$ for the ACL injury rate, but was not significant $\left(\mathrm{R}^{2}=0.13, \mathrm{~b}=0.059,95 \% \mathrm{CI}\right.$ -0.04 to $0.15, p=0.20)$. The 2 -year MA approach indicated a higher average annual increase, 23.1\%, than the regression model (figure 1). Similarly, the trend in the regression model indicated a non-significant average annual increase of $6.0 \%$ for the ACL match injury rate $\left(\mathrm{R}^{2}=0.15, \mathrm{~b}=0.056,95 \% \mathrm{CI}-0.03\right.$ to $0.01, \mathrm{p}=0.17$ ), whereas the 2-year MA approach indicated $16.7 \%$ (figure 2). Seasonal trend was not possible to analyse for training owing to four seasons with no training-related ACL injuries.

\section{Total ACL ruptures}

The majority of the total ruptures underwent ACL reconstruction $(138 / 140,98.6 \%)$; one player ended his career directly after the event and another returned to training after 92 days and to match play after 105 days without surgery.

\section{RTP rates}

Four total ruptures from the closing period of the 2014/2015 season were still under rehabilitation and not yet cleared for RTP. All other players returned to training, which means a remarkable 130 of 134 players $(97.0 \%)$ returned to the same playing level.

Five players returned to full team training, but never participated in match play (table 1); two players ended their careers and three players suffered reruptures. A majority of players were cleared for RTP within a year after ACL reconstruction (figure 3), with only five (3.7\%) and eight (9.7\%) players returning to training and match play later than 1 year. The median layoff times after ACL reconstruction were 201.5 (IQR 58.0) days (6.6 months) to training and 225.0 (IQR 80.3) days (7.4 months) to match play. Excluding players with careerending injuries $(\mathrm{N}=2)$, reruptures $(\mathrm{N}=3)$ and players still under rehabilitation $(\mathrm{N}=4)$, players' first match appearance after RTP was with the first team in 79 cases (35 friendly matches), with the under- 21 or reserve team in 49 cases (all league matches) and with a national team in one case (friendly match).

\section{Complication rates before return to match play}

In total, nine players (6.7\%) with ACL reconstruction (excluding the 4 players still under rehabilitation) suffered further knee 
Table 1 ACL injury characteristics and return-to-play rates in male professional football players

\begin{tabular}{|c|c|c|c|}
\hline & Training & Match & Total \\
\hline \multicolumn{4}{|l|}{ Total ruptures } \\
\hline Number of injuries & 28 & 112 & 140 \\
\hline Injury rate $(95 \% \mathrm{Cl})^{*}$ & $0.0138(0.0095$ to 0.0200$)$ & $0.3096(0.2573$ to 0.3726$)$ & $0.0586(0.0497$ to 0.0692$)$ \\
\hline Non-surgical treatment & 0 & 2 & 2 \\
\hline Return to training & - & 1 & 1 \\
\hline Return to match play & - & 1 & 1 \\
\hline Ligament reconstruction & 28 & 110 & 138 \\
\hline Return to training & 28 & $106 t$ & 134 \\
\hline Return to match play & 26 & 103 & 129 \\
\hline \multicolumn{4}{|l|}{ Partial ruptures } \\
\hline Number of injuries & 6 & 11 & 17 \\
\hline Injury rate $(95 \% \mathrm{Cl})^{*}$ & 0.0025 (0.0011 to 0.0056$)$ & 0.0304 (0.0168 to 0.0549$)$ & 0.0071 (0.0044 to 0.0115$)$ \\
\hline Non-surgical treatment & 6 & 9 & 15 \\
\hline Return to training & 6 & 8 & 14 \\
\hline Return to match play & 5 & 8 & 13 \\
\hline Ligament reconstruction & 0 & 2 & 2 \\
\hline Return to training & - & 2 & 2 \\
\hline Return to match play & - & 2 & 2 \\
\hline \multicolumn{4}{|l|}{ Overall } \\
\hline Number of injuries & 34 & 123 & 157 \\
\hline Injury rate $(95 \% \mathrm{Cl})^{*}$ & $0.0168(0.0120$ to 0.0235$)$ & 0.3401 (0.2850 to 0.4058$)$ & $0.0657(0.0562$ to 0.0769$)$ \\
\hline Non-surgical treatment & 6 & 11 & 17 \\
\hline Return to training & 6 & 9 & 15 \\
\hline Return to match play & 5 & 9 & 14 \\
\hline Ligament reconstruction & 28 & 112 & 140 \\
\hline Return to training & 28 & $108 t$ & 136 \\
\hline Return to match play & 26 & 105 & 131 \\
\hline
\end{tabular}

injury or underwent further knee surgery before their first match appearance. Two players reruptured their grafts during the rehabilitation and three players reruptured their grafts after return to training, but before they participated in match play. Two players had other ipsilateral knee surgery during their rehabilitation (arthroscopic clearing out procedures owing to repeated effusions) and another two players had ipsilateral surgery after return to training (arthroscopic cartilage debridement and arthroscopic meniscus repair). In addition, one player suffered a rectus femoris strain early after return to training, prolonging his time to return to match play after his ACL reconstruction.

The influence of total ACL injury on the playing career

There were 3-year follow-up data available for 93 players (8 repeat ruptures and 39 players injured later than November 2012 excluded from analysis). Eighty-one players (87.1\%) were still playing football 3 years after RTP, $60(64.5 \%)$ at the same level and $21(22.6 \%)$ at a lower level, and 12 players had ended their careers. The mean (SD) ages for those who played at the same level 3 years after RTP and those who were not, 24.5 (4.0) vs $25.3(6.0)$ years, did not differ significantly $(p=0.46)$.

\section{Partial ACL ruptures}

Two injuries involved the posterolateral (PL) bundle and underwent a PL bundle reconstruction with a semitendinosus tendon. The remaining 15 partial ruptures were all treated without ACL reconstruction, but two of these players had other ipsilateral knee surgery owing to concomitant injuries: the first player had meniscus surgery, and the second player had microfracture surgery.

\section{RTP rates}

One player with a partial rupture ended his career after this injury event owing to a history of ACL reconstruction twice in the contralateral knee. All other players returned to training (15 of 16 to the same playing level), but one player not to match play (table 1). Excluding the career-ending injury and the four with knee surgery, the median layoff times were 59.5 (IQR 50.5) days (2.0 months) to training and 75.0 (IQR 83.8) days (2.5 months) to match play.

Complication rates before return to match play

One injury was classified as a partial rerupture and was treated non-surgically. After only 10 days of football training, there was a new trauma resulting in a total graft rupture. No other complications for the partial ruptures were identified.

The influence of partial $A C L$ injury on the playing career

There were 3-year follow-up data available for 13 players (4 players injured later than November 2012). Ten players were still playing football 3 years after RTP, eight at the same level and two at a lower level, whereas three players had ended their careers.

\section{DISCUSSION}

The main finding of this study was that the ACL injury rate in male professional football players did not decline during the 


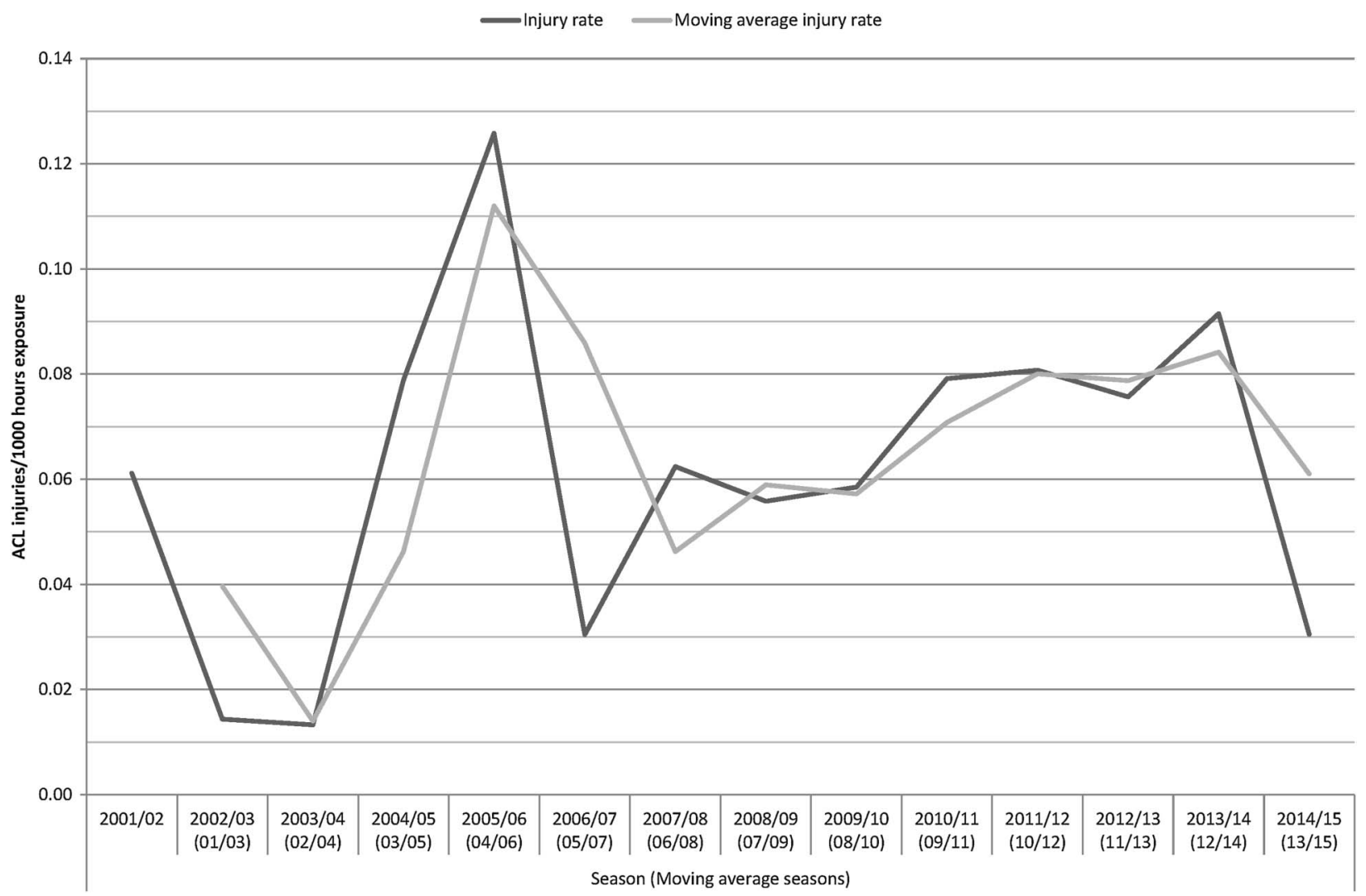

Figure 1 Seasonal trend for the ACL injury rate in male professional football players from 2001 to 2015.

2000s. Another important finding was that all players who underwent ACL reconstruction for a total rupture were able to return to training, but the ipsilateral rerupture rate $(4 \%)$ and the need for other ipsilateral knee surgery (3\%) before return to match play were not negligible. Finally, the RTP rate within a year after ACL reconstruction for a total rupture was very

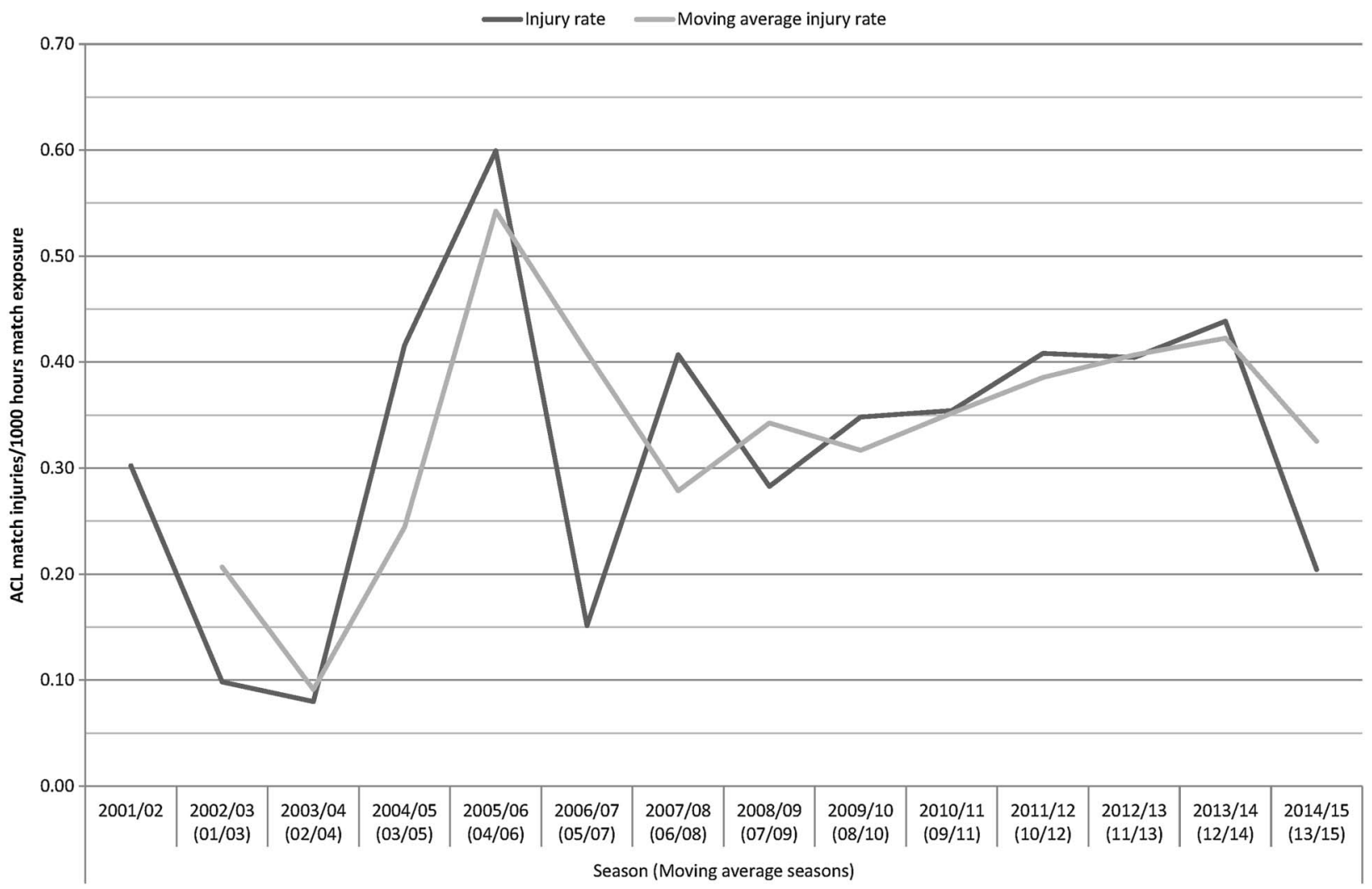

Figure 2 Seasonal trend for the ACL match injury rate in male professional football players from 2001 to 2015. 


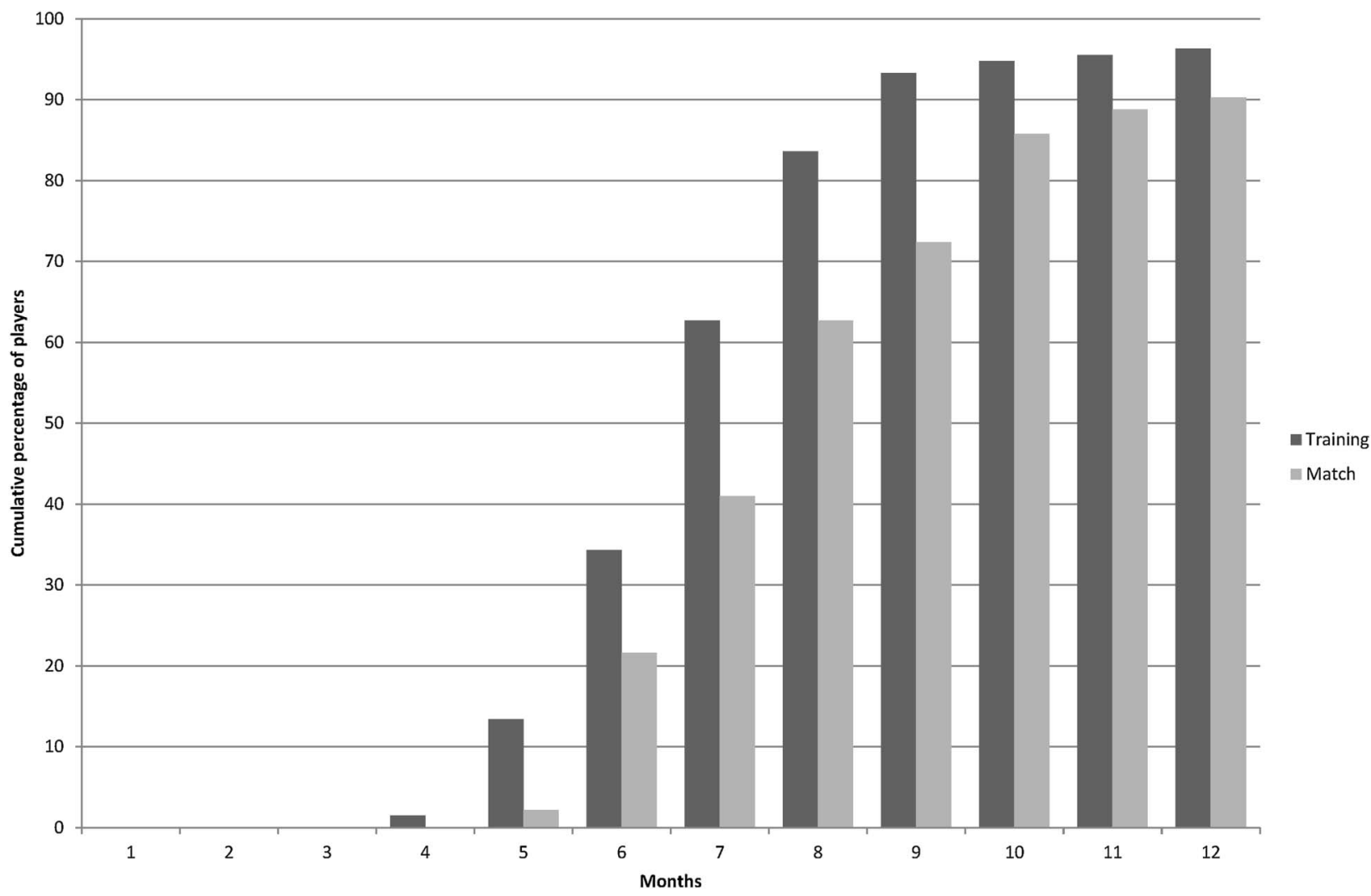

Figure 3 Cumulative percentage of $\mathrm{ACL}$ reconstructed male professional football players returning to training and match play within 12 months after surgery.

high (>90\%), but only $65 \%$ competed at the highest level 3 years later.

\section{ACL injury epidemiology}

The overall ACL injury rate in the current study was 0.066 per $1000 \mathrm{~h}$ or 0.43 per team per season, which extends the similar rate reported for this cohort up to the $2008 / 2009$ season. ${ }^{8}$ Only a few studies have investigated the development of injury rates over time in professional sports and previous studies from our group have shown conflicting trends; ligament injuries such as ankle sprain and MCL injury of the knee show decreasing trends, ${ }^{4} 5$ whereas hamstring injury seems to increase. ${ }^{16}$ For ACL injury, one study on male professional players in the USA reported an increase in the number of annual ACL injuries from 1996 to $2012 .^{2}$ In this study over 14 seasons, the ACL injury rate fluctuated during the period seasons, but remained essentially unchanged during the 2000s. The trend was rather for a non-significant increase than a decline over the years.

\section{Why has the $A C L$ injury rate not decreased at the professional level?}

The finding that the ACL injury rate in male professional football players is not declining is worrying, not the least as several high-quality randomised controlled trials have shown that prevention of ACL injuries is possible with neuromuscular training programmes. Although most research to date has been conducted in female players, ${ }^{18}{ }^{19}$ there is recent evidence that ACL injury rates can also be reduced in male players. ${ }^{20}$ Highly skilled professional male senior football players have, however, not been studied and it is possible that the underlying risk factors, injury mechanisms and preventive strategies could be different in this subgroup.
A debated risk factor in the literature and the football community is fatigue, but many of the ACL injuries actually occur early in the first half or among newly substituted players in the second half. ${ }^{8}$ This finding suggests that if fatigue is a risk factor, it is probably more an effect of accumulated fatigue over time, for example, owing to a congested match calendar ${ }^{21} 22$ than energy depletion per se in the match where the ACL injury occurs. In terms of potential different ACL injury mechanisms, a recent systematic video analysis showed that the injury mechanisms in professional male football players were similar to those previously described for female athletes, ${ }^{23}$ making this theory less likely. Finally, it could also be a problem with poor adoption of evidence-based knee-protective exercises in this setting, as has been shown recently for the case of hamstring injuries. $^{24}$ We speculate that the latter actually could be the main reason, and we therefore recommend that the club medical staff work in close collaboration with the head coach and the fitness coach in order to implement evidence-based preventive measures.

\section{High initial RTP rate within a year after ACL reconstruction}

It is well known that release for RTP after injury/surgery is a complex process depending on medical and non-medical factors. $^{25}$ In addition, a recent meta-analysis of 69 studies that included 7556 patients, Ardern et $a l^{26}$ reported that only $65 \%$ actually returned to their preinjury level following ACL reconstruction.

In male football players, however, several studies reported RTP rates of $76 \%$ up to almost $100 \% .{ }^{2} 689$ In this study, we found that $100 \%$ of all players treated with ACL reconstruction for a total rupture returned to football training. More than $90 \%$ of the players also returned to match play within a year after 
ACL reconstruction, which is considerably higher than in a recent Australian study on mixed team sports in which two-thirds of patients had not returned by 1 year. ${ }^{27}$ Possible reasons for this high RTP rate in our cohort might be early diagnostics, referral to experienced high-volume surgeons, daily supervised rehabilitation by qualified physiotherapists, and big financial motivation for players to continue to play professionally. ${ }^{28}$

\section{Subsequent $A C L$ injury after $A C L$ reconstruction}

Even if all ACL-reconstructed players were able to return to training, five players (4\%) suffered a rerupture during the final phase of the rehabilitation or before their first match appearance. In addition, another four players (3\%) suffered early reruptures within 3 months after their first match appearance (data not shown), one even in his first match after release from rehabilitation. In this respect, the emerging evidence for unacceptably high rates of subsequent ipsilateral graft rupture or contralateral ACL rupture after ACL reconstruction is worrying. ${ }^{29}{ }^{30}$ Subsequent ACL ruptures are seen especially in younger athletes who return to sports and were, in a recent systematic review by Wiggins et al, ${ }^{29}$ calculated to be approximately 35 times higher than those for uninjured subjects. The risk for ipsilateral graft rupture seems to be greatest in the first 2 years after ACL reconstruction, and a relatively higher proportion of contralateral ACL ruptures are seen with increasing follow-up periods. ${ }^{30}$ The number of contralateral ACL ruptures was low in this study, and this is most probably explained by the limited individual follow-up times after 5 years postreconstruction.

From a strict medical perspective, a non-contact ipsilateral graft and contralateral ACL rupture, or even another secondary knee injury, occurring in the final phase of the rehabilitation period or early after RTP should be regarded as a treatment failure. Consequently, and in the light that only a minority of clinical studies on ACL reconstruction report objective criteria for return to sports, ${ }^{31}$ our results therefore strongly imply that creating and validating clinical RTP criteria and test batteries to prevent subsequent injury should be a prioritised research area in the near future.

\section{Methodological considerations}

The study design strictly adhered to the consensus statement of football injury surveillance, ${ }^{32}$ and the general strengths and limitations of injury surveillance studies will therefore not be repeated here in detail. Specifically for this substudy, the rigorous ACL injury data monitoring and the large homogeneous sample of professional football players are two important strengths.

This study also has some important limitations. First, in our previous injury time-trend analyses, we have focused on frequent injuries including hamstring injuries, MCL injuries of the knee, and ankle sprains, ${ }^{3-5} 16$ and have found great agreement between the regression and the 2-year MA models. In this study, however, there was an apparent discrepancy between the models with the 2-year MA approach indicating higher annual increases. The most plausible explanation is that $2005 / 2006$ was an 'extreme season' with an ACL injury rate of 0.13 per $1000 \mathrm{~h}$ and is thus represented twice in the MA approach. Consequently, the MA approach should be used with caution in small samples with fluctuating injury rates between seasons.

Second, we have not examined the players or read the MRIs ourselves and were thus dependent on the clubs' medical staff in classifying the ACL injuries as partial or total ruptures. Although the clinical and radiological pictures are often straightforward, it cannot be fully ruled out that a partial rupture might have been classified as a total rupture and vice versa.

Third, the participating clubs were not provided with any specific RTP criteria in the study manual. It is therefore likely that layoff times varied between clubs due to different diagnostics and treatment algorithms.

Fourth, return to match play is more associated with nonmedical factors than medical factors compared with return to training. For example, participation in match play also depends on the 'shirt number', player performance, playing position, match type, period of season, etc, all of which could influence whether a player is selected by the coach. We have therefore also included first team friendly, reserve team, under- 21 and national team matches in the return to match play statistics and not first team competitive matches exclusively.

\section{CONCLUSION}

The ACL injury rate was 0.4 per team per season, which means that a club on average will see an ACL injury every second season. The training environment provides a very low risk of ACL injury; the match play rate is 20 -fold higher than during training. In the 2000s, there has been no decline in the overall ACL injury rate or the ACL match injury rate. All players were able to return to training after ACL reconstruction, but the rerupture $(4 \%)$ and the need for other ipsilateral knee surgery (3\%) rates before return to match play was not trivial. Almost two-thirds of players with ACL reconstruction for a total rupture played at the same level 3 years after RTP.

\section{What are the findings?}

- All players who underwent $\mathrm{ACL}$ reconstruction for a total rupture returned to training, but the rerupture rate before returning to match play was $4 \%$.

- Only two-thirds of players who ruptured their ACL were still playing at the highest level 3 years later.

- The ACL injury rate in male professional football players showed no declining trend during the 2000s.

\section{How might it impact on clinical practice in the future?}

- Novel primary and secondary preventive measures are urgently needed in this professional men's football setting.

- Research should focus on valid and widely accepted clinical return-to-play criteria to prevent recurrent injury.

Twitter Follow @MarkusWalden, @MHgglund, @HenkeMag, @janekstrand, @frgsweden.

Acknowledgements The authors would like to thank the participating clubs (including contact persons, coaching staff, medical staff and all players) for their participation in the study. The Football Research Group has been established in Linköping, Sweden, in collaboration with Linköping University and through grants from the UEFA, the Swedish Football Association, the Football Association Premier League Limited, and the Swedish National Centre for Research in Sports.

Contributors MW was responsible for the conception of the study and all authors have been involved in the data collection and computerisation. MW and HM conducted the analyses which were planned and checked with MH and JE. All the authors contributed to the interpretation of findings and had full access to all data. MW wrote the first draft of the manuscript which was critically revised by MH, HM 
and JE. The final manuscript has been approved by all authors. MW is the study guarantor.

Funding This study was funded by grants from the UEFA, the Swedish Football Association, the Football Association Premier League Limited, and the Swedish National Centre for Research in Sports.

Competing interests None declared.

Ethics approval The study protocols were approved by the Regional Ethical Review Board in Linköping, Sweden, and the UEFA Football Development Division and the UEFA Medical Committee.

Provenance and peer review Not commissioned; externally peer reviewed.

\section{REFERENCES}

1 von Porat A, Roos EM, Roos H. High prevalence of osteoarthritis 14 years after an anterior cruciate ligament tear in male soccer players: a study of radiographic and patient relevant outcomes. Ann Rheum Dis 2004;63:269-73.

2 Erickson BJ, Harris JD, Cvetanovich GL, et al. Performance and return to sport after anterior cruciate ligament reconstruction in male Major League Soccer players. Ort $\mathrm{f}$ Sports Med 2013;1: 2325967113497189.

3 Ekstrand J, Hägglund $\mathrm{M}$, Kristenson $\mathrm{K}$, et al. Fewer ligament injuries but no preventive effect on muscle injuries and severe injuries: an 11-year follow-up of the UEFA Champions League injury study. Br I Sports Med 2013;47:732-7.

4 Lundblad M, Waldén M, Magnusson $\mathrm{H}$, et al. The UEFA injury study: 11-year data concerning $346 \mathrm{MCL}$ injuries and time to return to play. Br I Sports Med 2013:47:759-62.

5 Waldén $M$, Hägglund $M$, Ekstrand J. Time-trends and circumstances surrounding ankle injuries in men's professional football: an 11-year follow-up of the UEFA Champions League injury study. Br I Sports Med 2013;47:748-53.

6 Brophy RH, Schmitz L, Wright RW, et al. Return to play and future ACL injury risk after $\mathrm{ACL}$ reconstruction in soccer athletes from the Multicenter Orthopedic Outcomes Network (MOON) group. Am I Sports Med 2012;40:2517-22.

7 Roi GS, Nanni G, Tencone F. Time to return to professional soccer matches after ACL reconstruction. Sport Sci Health 2006;1:142-5.

8 Waldén $\mathrm{M}$, Hägglund $\mathrm{M}$, Magnusson $\mathrm{H}$, et al. Anterior cruciate ligament injury in elite football: a prospective three-cohort study. Knee Surg Sports Traumatol Arthrosc 2011:19:11-19.

9 Zaffagnini S, Grassi A, Marcheggiani Muccioli GM, et al. Return to sport after anterior cruciate ligament reconstruction in professional soccer players. Knee 2014;21:731-5.

10 Roi GS, Creta D, Nanni G, et al. Return to official Italian first division soccer games within 90 days after anterior cruciate ligament reconstruction: a case report. J Orthop Sport Phys Ther 2005;35:52-66.

11 Weiler R, Monte-Colombo M, Mitchell A, et al. Non-operative management of a complete anterior cruciate ligament injury in an English Premier League football player with return to play in less than 8 weeks: applying common sense in the absence of evidence. BMJ Case Rep published online 26 Apr 2015; doi:10.1136/ bcr-2014-208012

12 Waldén $M$, Hägglund $M$, Ekstrand J. High risk of new knee injury in elite footballers with previous anterior cruciate ligament injury. Br I Sports Med 2006;40:158-62.

13 Waldén $M$, Hägglund $M$, Ekstrand J. Injuries in Swedish elite football—a prospective study on injury definitions, risk for injury and injury pattern during 2001. Scand I Med Sci Sports 2005;15:118-25.

14 Waldén $M$, Hägglund $M$, Ekstrand J. UEFA Champions League study: a prospective study of injuries in professional football during the 2001-2002 season. Br J Sports Med 2005;39:542-6.
15 Hägglund M, Waldén M, Bahr R, et al. Methods for epidemiological study of injuries to professional football (soccer) players: developing the UEFA model. Br J Sports Med 2005;39:340-6.

16 Ekstrand J, Waldén $M$, Hägglund $M$. Hamstring injuries have increased by $4 \%$ annually in men's professional football, since 2001: a 13-year longitudinal analysis of the UEFA Elite Club Injury Study. Br I Sports Med 2016;50: $731-7$

17 Lindenfeld TN, Schmitt DJ, Hendy MP, et al. Incidence of injury in indoor soccer. Am J Sports Med 1994;22:364-71.

18 Gilchrist J, Mandelbaum BR, Melancon $\mathrm{H}$, et al. A randomized controlled trial to prevent noncontact anterior cruciate ligament injury in female collegiate soccer players. Am J Sports Med 2008;36:1476-83.

19 Waldén $\mathrm{M}$, Atroshi I, Magnusson $\mathrm{H}$, et al. Prevention of acute knee injuries in adolescent female football players: cluster randomised controlled trial. BMJ 2012;344:e3042

20 Silvers-Granelli $\mathrm{H}$, Mandelbaum B, Adeniji $\mathrm{O}$, et al. Efficacy of the FIFA 11+ injury prevention program in the collegiate male soccer player. Am I Sports Med 2015;43:2628-37.

21 Dupont $\mathrm{G}$, Nedelec $\mathrm{M}, \mathrm{McCall} \mathrm{A}$, et al. Effect of 2 soccer matches in a week on physical performance and injury rate. Am J Sports Med 2010;38:1752-8.

22 Carling C, McCall A, Le Gall F, et al. The impact of short periods of match congestion on injury risk and patterns in an elite football club. Br J Sports Med 2016;50:764-8.

23 Waldén $\mathrm{M}$, Krosshaug T, Bjørneboe J, et al. Three distinct mechanisms predominate in non-contact anterior cruciate ligament injuries in male professional football players: a systematic video analysis of 39 cases. Br I Sports Med 2015;49: 1452-60

24 Bahr R, Thorborg K, Ekstrand J. Evidence-based hamstring injury prevention is not adopted by the majority of Champions League or Norwegian Premier League football teams: the Nordic Hamstring survey. Br J Sports Med 2015;49: 1466-71.

25 Creighton DW, Shrier I, Shultz R, et al. Return-to-play in sport: a decision-based model. Clin J Sport Med 2010;20:379-85.

26 Ardern CL, Taylor NF, Feller JA, et al. Fifty-five per cent return to competitive sport following anterior cruciate ligament reconstruction surgery: an updated systematic review and meta-analysis including aspects of physical functioning and contextual factors. Br J Sports Med 2014;48:1543-52.

27 Ardern $\mathrm{CL}$, Webster $\mathrm{KE}$, Taylor NF, et al. Return to the preinjury level of competitive sport after anterior cruciate ligament reconstruction surgery: two-thirds of patients have not returned by 12 months after surgery. Am J Sports Med 2011;39:538-43

28 Ekstrand J. A 94\% return to elite level football after ACL surgery: a proof of possibilities with optimal caretaking or sign of knee abuse? Knee Surg Sports Traumatol Arthrosc 2011;19:1-2.

29 Wiggins AJ, Grandhi RK, Schneider DK, et al. Risk of secondary injury in younger athletes after anterior cruciate ligament reconstruction: a systematic review and meta-analysis. Am J Sports Med. Published Online First: [15 January 2016].

30 Waldén M. Return to sports after ACL reconstruction surgery: a risk for further joint injury? In: Sanchis-Alfonso V, Monllau JC, ed. The ACL-deficient knee. A problem solving approach. 1st edn. London: Springer-Verlag, 2013:183-8.

31 Barber-Westin SD, Noyes FR. Factors used to determine return to unrestricted sports activities after anterior cruciate ligament reconstruction. Arthroscopy 2011;27:1697-705

32 Fuller CW, Ekstrand J, Junge $A$, et al. Consensus statement on injury definitions and data collection procedures in studies of football (soccer) injuries. $\mathrm{Br}$ I Sports Med 2006:40:193-201. 